Annals of International Medical and Dental Research

E-ISSN: 2395-2822 | P-ISSN: 2395-2814

Vol-8, Issue-1 | January-February 2022

DOI: 10.53339/aimdr.2022.8.1.2

Page no- 07-11 | Section- Research Article (Paediatrics)

\title{
Prevalence of Depression among 6-15 Years of Age
}

\section{Harshindar Kaur ${ }^{*}$, Sukhmani Kaur ${ }^{2}$, Tejvir Singh Shimar ${ }^{3}$, Devina Singh ${ }^{4}$}

\begin{abstract}
${ }^{1}$ Associate Professor, Department of Paediatrics, GMC Patiala, Punjab, India. Email: drharshpatiala@yahoo.com Orcid ID: 0000-0002-0913-7068

2Medical Officer, PCMS, Patiala, Email: dr.sukhmanikaur29@gmail.com Orcid ID: 0000-0001-7773-0448

3Senior Resident, Department of Paediatrics, GMC Patiala, Punjab, India. Email: lallyshimar@yahoo.com Orcid ID: 0000-0002-7301-6164 4Junior Resident, Department of Paediatrics, GMC Patiala, Punjab, India. Email: kvspthirteen@gmail.com

Orcid ID: 0000-0003-0490-1482

*Corresponding author

Received: 05 September 2021

Revised: 11 October 2021

Accepted: 19 October 2021

Published: 22 December 2021

Abstract

Background: Aim: To assess cases of depression in children. Methods: Eighty- nine children age ranged 6-15 years of either gender were included. The level of depression among children was determined with Patient Health Questionnaire (PHQ-9). Results: Age group 6-10 years had 24, 10-12 years had 30 and 12-15 years had 35 children. Boys were 55 and girls were 34 . Residence was urban in 39 and rural in 50. Family type was joint in 52 and nuclear in 37 . A significant difference was observed $(\mathrm{P}<0.05)$. $35 \%$ not at all felt little interest or pleasure in doing things, $52 \%$ not at all felt down depressed, $46 \%$ not at all felt trouble falling or staying asleep, $34 \%$ not at all felt tired, $60 \%$ not at all felt bad about yourself, $68 \%$ not at all felt trouble concentrating on things, $70 \%$ not at all felt moving or speaking so slowly that other people could have noticed, $82 \%$ not at all felt thoughts that you would be better off dead or of hurting yourself in the some way. Level of depression was not at all in $12 \%$, minimal in $35 \%$, mild in $42 \%$, moderate in $10 \%$ and severe in $1 \%$. The difference was significant $(\mathrm{P}<0.05)$. Conclusions: Most of the children had mild and minimal depression. Most of the children had feeling tired.
\end{abstract}

Keywords:- Children, Depression, Patient Health Questionnaire.

\section{INTRODUCTION}

Depression is a common psychiatric condition that negatively affects feeling, thinking and acting. Depression causes feelings of sadness and/or a loss of interest in activities once enjoyed.[1] Depression can lead to a multiple emotional and physical problems and can decrease a person's ability to function at work and at home. The young people in the age group of 10-24 are characterized by immense growth and development. It is a stage of vulnerability often influenced by several risk and protective factors that affect their health and safety.[2]
According to the estimates of the World Health Organization, 322 million people, amounting to $4.4 \%$ of the world population, suffer from depression. Depression is one of the leading causes of disease burden worldwide and is ranked as the second leading cause of disability. It is also considered as a major contributor to the global burden of diseases.[3]

Symptoms of depression vary as per age and developmental level; affective symptoms and cognitive distortions in childhood are similar to adults, whereas biological symptoms such as changes in sleep and appetite are different. ${ }^{4]}$ Hypersomnia, decreased appetite, and weight loss are more common in adolescents as 
Annals of International Medical and Dental Research

E-ISSN: 2395-2822 | P-ISSN: 2395-2814

Vol-8, Issue-1 | January-February 2022

DOI: 10.53339/aimdr.2022.8.1.2

Page no- 07-11 | Section- Research Article (Paediatrics)

compared to children. Delusions are also uncommon in children. Negative cognitions such as low self-esteem, hopelessness, and negative attributions are common in children.[5] Considering this, we attempted this study to assess cases of depression among 8-15 years old children.

\section{MATERIAL AND METHODS}

The present prospective study observational study comprised of eighty- nine children age ranged 6-15 years of either gender. A consent from parents was obtained. Institutional review board approved this study.

We recorded demographic profile of all children. The level of depression among children was determined with Patient Health Questionnaire (PHQ-9). The PHQ-9 is a nine items tool covering DSM-IV criteria for depression such as anhedonia, depressed mood, trouble sleeping, feeling tired, change in appetite, guilt, self-blame, or worthlessness, trouble concentrating, feeling slowed down or restless and thoughts of being better off dead or hurting oneself was recorded. Each item is rated on a 4-point scale from 0 to 3 ( 0 - never, 1 - several days, 2 - more than half the time, and 3 - nearly every day). Descriptive statistics were performed using appropriate test with the level of significance below 0.05 .

\section{RESULTS}

[Table 1] shows that age group 6-10 years had $24,10-12$ years had 30 and 12-15 years had 35 children. Boys were 55 and girls were 34 . Residence was urban in 39 and rural in 50. Family type was joint in 52 and nuclear in 37. A significant difference was observed ( $\mathrm{P}<$ 0.05).

[Table 3, Figure 1] shows that 35\% not at all felt little interest or pleasure in doing things, 52\% not at all felt down depressed, $46 \%$ not at all felt trouble falling or staying asleep, 34\% not at all felt tired, $60 \%$ not at all felt bad about yourself, $68 \%$ not at all felt trouble concentrating on things, $70 \%$ not at all felt moving or speaking so slowly that other people could have noticed, $82 \%$ not at all felt thoughts that you would be better off dead or of hurting yourself in the some way. A significant difference was observed $(\mathrm{P}<0.05)$.

[Table 4] shows that level of depression was not at all in $12 \%$, minimal in $35 \%$, mild in $42 \%$, moderate in $10 \%$ and severe in $1 \%$. The difference was significant $(\mathrm{P}<0.05)$.

Table 1: Characteristics of subjects

\begin{tabular}{|l|l|l|l|}
\hline Parameters & Variables & Number & P value \\
\hline \multirow{4}{*}{ Age group (years) } & $6-10$ years & 24 & $<0.05$ \\
\cline { 2 - 3 } & $10-12$ years & 30 & \\
\cline { 2 - 3 } & $12-15$ years & 35 & $>0.05$ \\
\hline \multirow{2}{*}{ Gender } & Boys & 55 & \multirow{2}{*}{$<0.05$} \\
\cline { 2 - 3 } & Girls & 34 & \\
\hline \multirow{2}{*}{ Family type } & Urban & 39 & \multirow{2}{*}{} \\
\cline { 2 - 3 } & Rural & 50 & 52 \\
\hline
\end{tabular}


Annals of International Medical and Dental Research

E-ISSN: 2395-2822 | P-ISSN: 2395-2814

Vol-8, Issue-1 | January-February 2022

DOI: 10.53339/aimdr.2022.8.1.2

Page no- 07-11 | Section- Research Article (Paediatrics)

Table 2: Assessment of PHQ

\begin{tabular}{|c|c|c|c|c|c|}
\hline PHQ & Not at all & Several days & $\begin{array}{l}\text { More than half } \\
\text { the day }\end{array}$ & $\begin{array}{l}\text { Nearly every } \\
\text { year }\end{array}$ & P value \\
\hline $\begin{array}{l}\text { Little interest or pleasure in } \\
\text { doing things }\end{array}$ & $35 \%$ & $40 \%$ & $22 \%$ & $3 \%$ & 0.04 \\
\hline Feeling down depressed & $52 \%$ & $30 \%$ & $10 \%$ & $8 \%$ & 0.02 \\
\hline $\begin{array}{l}\text { Trouble falling or staying } \\
\text { asleep }\end{array}$ & $46 \%$ & $34 \%$ & $15 \%$ & $5 \%$ & 0.02 \\
\hline Feeling tired & $34 \%$ & $41 \%$ & $15 \%$ & $10 \%$ & 0.02 \\
\hline Feeling bad about yourself & $60 \%$ & $25 \%$ & $12 \%$ & $3 \%$ & 0.04 \\
\hline $\begin{array}{l}\text { Trouble concentrating on } \\
\text { things }\end{array}$ & $68 \%$ & $22 \%$ & $8 \%$ & $2 \%$ & 0.02 \\
\hline $\begin{array}{l}\text { Moving or speaking so slowly } \\
\text { that other people could have } \\
\text { noticed }\end{array}$ & $70 \%$ & $12 \%$ & $10 \%$ & $8 \%$ & 0.03 \\
\hline $\begin{array}{l}\text { Thoughts that you would be } \\
\text { better off dead or of hurting } \\
\text { yourself in the some way }\end{array}$ & $82 \%$ & $10 \%$ & $4 \%$ & $4 \%$ & 0.04 \\
\hline
\end{tabular}

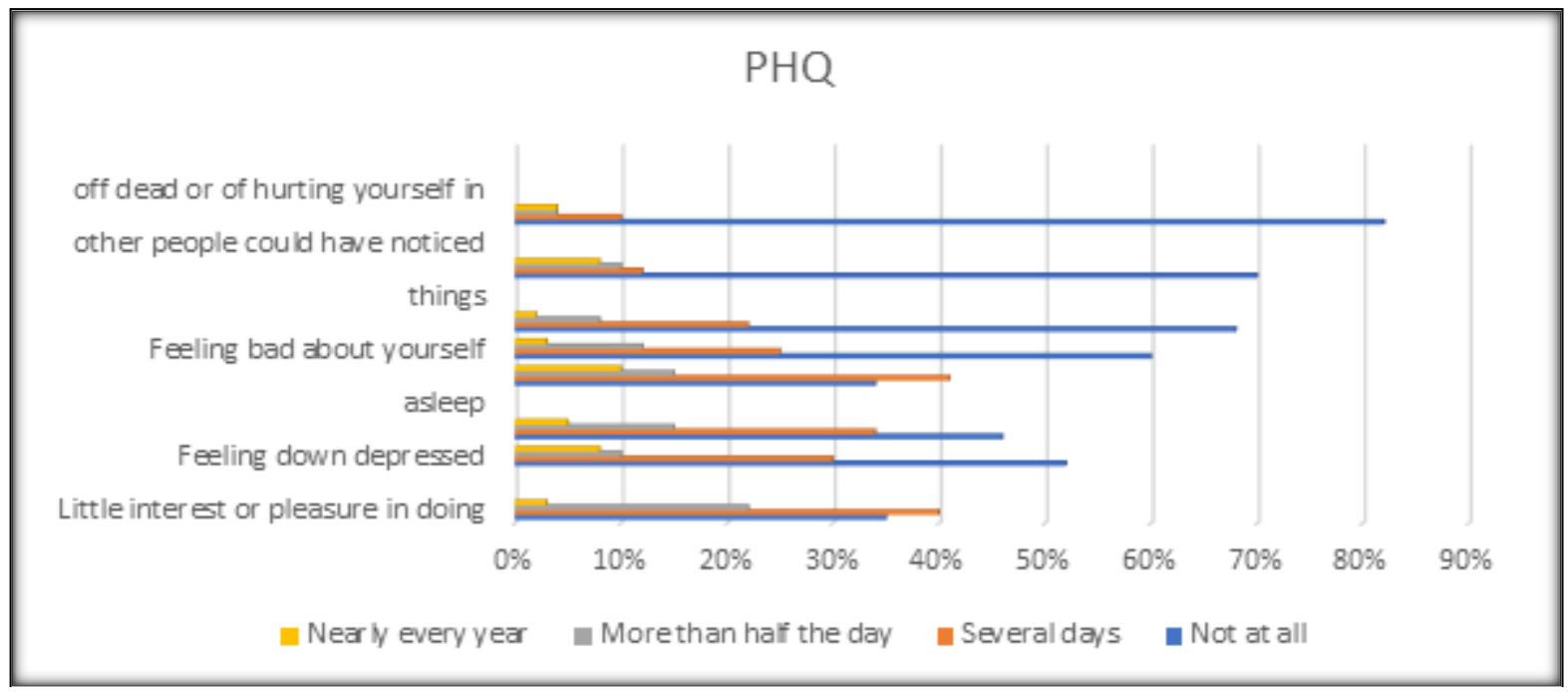

Figure 1: Assessment of PHQ

Table 3: Level of depression among patients

\begin{tabular}{|l|l|l|}
\hline Variables & Percentage & P value \\
\hline Not at all & $12 \%$ & 0.01 \\
\cline { 1 - 2 } Minimal & $35 \%$ & \\
\cline { 1 - 2 } & $42 \%$ & \\
\hline Moderate & $10 \%$ & \\
\hline Severe & $1 \%$ & \\
\hline
\end{tabular}

Copyright: (The author(s), published in Annals of International Medical and Dental Research, Vol-8, Issue-1. This is an open access article under the Attribution-Non Commercial 2.0 Generic (CC BY-NC 2.0) license. (https://creativecommons.org/licenses/by-nc/2.0/) 
Annals of International Medical and Dental Research

E-ISSN: 2395-2822 | P-ISSN: 2395-2814

Vol-8, Issue-1 | January-February 2022

DOI: 10.53339/aimdr.2022.8.1.2

Page no- 07-11 | Section- Research Article (Paediatrics)

\section{DISCUSSION}

Both parent and child interviews are needed for diagnosis of depression. Open-ended questions are used for initial assessment of depression as well as comorbid conditions such as anxiety, attention-deficit/hyperactivity disorder, and conduct disorder. [6] Furthermore, contextual factors such as family environment, school problems, and interpersonal difficulties need to be assessed to ascertain their role as precipitating and perpetuating factors for depression.[7] Assessment of risk for suicide is also essential to monitor the ongoing suicide risk if any.[8] More structured assessment is then taken up to assess symptoms and severity of depression. All these initial assessments are continued on an ongoing basis to monitor clinical progress. [9] In addition to clinical interviews, other methods like pictorial instruments can be used, which can be useful for better clinical understanding of mental state of children because of their age appropriateness in communicating abstract thoughts and emotions.[10] This study was conducted to assess cases of depression among 8-15 years old children.

We found that age group 6-10 years had 24, 1012 years had 30 and 12-15 years had 35 children. Boys were 55 and girls were 34 . Residence was urban in 39 and rural in 50. Family type was joint in 52 and nuclear in 37. Srivastava et al,[11] assessed cases of depression in young adults. 62 patients diagnosed with depression were recruited. A questionnaire comprised of family type, residence was used. The Patient Health Questionnaire (PHQ-9) was used to assess the level of depression among the respondents. Out of 62 patients, males were 20 and females were 42. Age group 20-30 years had 12 males and 30 females, 30-40 years had 6 males and 7 females and $>40$ years had 2 males and 5 females. 14 males and 30 females had nuclear and 6 males and 12 females had joint family, residence was rural in 6 males and 32 females and urban in 14 males and 10 females. The difference was significant $(\mathrm{P}<0.05)$. The level of depression was not at all in $10 \%$, minimal in 34\%, mild in $40 \%$, moderate in $14 \%$ and severe in $2 \%$. The difference was significant $(\mathrm{P}<0.05)$.

We observed that $35 \%$ not at all felt little interest or pleasure in doing things, $52 \%$ not at all felt down depressed, $46 \%$ not at all felt trouble falling or staying asleep, 34\% not at all felt tired, $60 \%$ not at all felt bad about yourself, $68 \%$ not at all felt trouble concentrating on things, $70 \%$ not at all felt moving or speaking so slowly that other people could have noticed, $82 \%$ not at all felt thoughts that you would be better off dead or of hurting yourself in the some way. Glied et al,[12] examined the correlates and consequences of high levels of depressive symptoms among adolescents. Secondary analysis of the 1997 Commonwealth Fund Survey of the Health of Adolescent Girls, a survey of a nationally representative sample of 4648 adolescent boys and girls between the ages of 10 and 18 years, inclusive, conducted in school settings. The self-administered questionnaire contains a screening instrument for depression based on the Children's Depression Inventory. After controlling for socio-demographics, life events, sexual abuse, physical abuse, and exposure to violence, relative to other children, children and adolescents with high degrees of depressive symptoms missed about 1 day more of school in the month preceding the survey $(\mathrm{P}<.05)$ and 
Annals of International Medical and Dental Research

E-ISSN: 2395-2822 | P-ISSN: 2395-2814

Vol-8, Issue-1 | January-February 2022

DOI: 10.53339/aimdr.2022.8.1.2

Page no- 07-11 | Section- Research Article (Paediatrics)

had higher odds of smoking (odds ratio, 1.84; $\mathrm{P}<.001$ ), bingeing (odds ratio, 2.02; $\mathrm{P}<.001$ ), and suicidal ideation.

\section{REFERENCES}

1. Birmaher B, Brent D; AACAP Work Group on Quality Issues, Bernet W, Bukstein O, Walter H, et al. Practice parameter for the assessment and treatment of children and adolescents with depressive disorders. J Am Acad Child Adolesc Psychiatry. 2007;46(11):1503-26. doi: 10.1097/chi.0b013e318145ae1c.

2. Kovacs M. Presentation and course of major depressive disorder during childhood and later years of the life span. J Am Acad Child Adolesc Psychiatry. 1996;35(6):705-15. doi: 10.1097/00004583-199606000-00010.

3. Choe CJ, Emslie GJ, Mayes TL. Depression. Child Adolesc Psychiatr Clin N Am. 2012;21(4):807-29. doi: 10.1016/j.chc.2012.07.002.

4. Roseman M, Kloda LA, Saadat N, Riehm KE, Ickowicz A, Baltzer F, et al. Accuracy of Depression Screening Tools to Detect Major Depression in Children and Adolescents: A Systematic Review. Can J Psychiatry. 2016;61(12):746-757. doi: 10.1177/0706743716651833.

5. Otte C, Gold SM, Penninx BW, Pariante CM, Etkin A, Fava M, et al. Major depressive disorder. Nat Rev Dis Primers. 2016;2:16065. doi: 10.1038/nrdp.2016.65.

6. Pandian RD, Sreeranjini T, Aiman A, John S, Shishir K, Prabhu S. A study on the prevalence of depression among young adults in South India. Indian J Mental Health. 2017;4:24-9.

7. Auerbach RP, Kim JC, Chango JM, Spiro WJ, Cha C, Gold J, Esterman M, Nock MK. Adolescent

\section{CONCLUSIONS}

Authors found that most of the children had mild and minimal depression. Most of the children had feeling tired.

nonsuicidal self-injury: examining the role of child abuse, comorbidity, and disinhibition. Psychiatry Res. 2014;220(1-2):579-84. doi: 10.1016/j.psychres.2014.07.027.

8. Auerbach RP, Eberhart NK, Abela JR. Cognitive vulnerability to depression in Canadian and Chinese adolescents. J Abnorm Child Psychol. 2010;38(1):57-68. doi:10.1007/s10802-009-9344-y

9. Olfson M, Schoenbaum M. Link between FDA antidepressant warnings and increased suicide attempts in young people is questionable. BMJ. 2014;349:g5614. doi: 10.1136/bmj.g5614.

10. Brent D, Emslie G, Clarke G, Wagner KD, Asarnow JR, Keller M, et al. Switching to another SSRI or to venlafaxine with or without cognitive behavioral therapy for adolescents with SSRI-resistant depression: the TORDIA randomized controlled trial. JAMA. 2008;299(8):901-913. doi: 10.1001/jama.299.8.901.

11. Srivastava JS. Assessment of cases of Depression in young adults. J Adv Med Dent Scie Res. 2021;9(1):68-71.

12. Glied S, Pine DS. Consequences and correlates of adolescent depression. Arch Pediatr Adolesc Med. 2002;156(10):1009-14. 10.1001/archpedi.156.10.1009.

doi:

Source of Support: Nil, Conflict of Interest: None declared 